\title{
Acoustic method of jet grinding study and control
}

\author{
Nataliya Pryadko ${ }^{1, *}$, Kateryna Ternova $^{1}$, Hennadii Strelnykov ${ }^{1}$, Lev Muzyka ${ }^{1}$, and Inna \\ Verkhorobina $^{2}$ \\ ${ }^{1}$ The Institute of Technical Mechanics of the National Academy of Sciences of Ukraine and the State \\ Space Agency of Ukraine, 49005, Dnipro, Liashko-Popelia Str., 15, Ukraine \\ ${ }^{2}$ Institute of Geotechnical Mechanics named by N. Poljakov of National Academy of Sciences of \\ Ukraine, 49005, Dnipro, Simferopolska Str., 2a, Ukraine
}

\begin{abstract}
Jet grinding considers a rather energy-intensive production. For obtaining high mill productivity, it is necessary to control the process in order to prevent the transfer the energy intensity value to a critical one. This work shows the possibilities of jet grinding studying based on the process acoustic signal analysis and to develop a mill mode control system to achieve optimum productivity. There were determined that decrease in the activity and maximum amplitudes of the acoustic signals in the grinding zone is a sign of deviation from the optimal fine grinding mode, which leads to a decrease in the mill productivity and requires timely material loading. For control of ground product quality it's necessary to control the frequency dispersion of signals corresponding to the control class, and check the absence or presence of signals corresponding to other size classes for zone behind the classifier. The developed automated control system of jet grinding allows implementing the optimal parameters of the mill operation by control the acoustic parameters of the grinding zone for optimum jet loading with material. The dispersion control of the ready product is based on acoustic monitoring of a two-phase flow in the product transportation zone.
\end{abstract}

\section{Introduction}

Jet grinding considers a rather energy-intensive production. Despite the ever increasing demand for fine powders in various industries, jet and vortex mills cannot win in terms of the ball mill popularity and prevalence. However, this type of equipment for processing materials has found its place in production. Jet grinding is indispensable in obtaining thin and ultrathin "pure" materials, i.e. materials without introducing any impurities. And with the creation of a new process control method, there was a real possibility of reducing the jet mill energy consumption while maintaining their optimum performance.

It is known that the energy expended on grinding, many times exceeds the increase in the free surface energy of a solid obtained by reducing the grain size. The energy efficiency calculated by the surface energy is about $0.1 \%$ [1]. The rest of energy is spent on the

\footnotetext{
*Corresponding author: np-2006@ukr.net
} 
elastic and plastic deformation of the grains and operation surfaces of the mill, on the transfer of kinetic energy to the fragments of grains, on the friction of the grains between themselves, on the abrasion of machines, on ineffective loads that do not lead to the destruction of particles, on sound waves, etc. In addition, in real conditions the process of destruction is continuous, i.e. some of the particles did not collapse, an excessive load was applied to the other, and part of the energy was lost. The grinding technological task at the cconcentrating factories is the mineral disclosing of finely disseminated ores. The disclose should be carried out with minimal over grinding of inclusions. Energy is additionally spent on over grinding, and the formed fine particles worsen the conditions of mineral separation, that leads to the loss of the useful component [2].

To reduce the influence of these factors in the industry, grinding technology in closed cycles is used. The ideology of closed cycles is that, due to the movement of the transporting medium (water, air), consciously non ground material is extracted from the mill, which is divided by the external classifier (hydraulic and pneumatic classifiers, cyclones, screens) into a ready product and a circulating load led for regrinding in the same mill [3].

The energy is supplied to the grinding material in the mill through a grinding medium or gas with a certain intensity, which consumes energy for the deformation of the material being grinded and the formation of a new surface upon its destruction. The specific energy consumption per unit mass of the ground material in this case amounts as $E_{s p}=N / Q$, then it follows that the reduction of energy consumption during grinding in this unit can be achieved by increasing its productivity provided that the technological task is fulfilled obtaining a ground product with a given dispersion.

The analysis of the energy features of fine and ultrafine grinding in jet and drum mills defined the existence of a critical level of process energy intensity, the crossing which changes the dependence of the newly created surface on the energy consumption of its formation [4]. Numerous studies of the grinding laws made it possible to define the dependence that connects the newly formed specific surface during grinding with the energy consumption for this process. For rather large particles, this dependence is linear with a slope close to a straight line. As fine particles appear, the energy for the destruction of such particles has to be spent more, and therefore the sensitivity (angle of slope) decreases. The third section corresponds to conditions when the number of fine particles has significantly increased, therefore it is necessary to destroy particles that are close to the molecules size. Naturally, for such destruction it is necessary to spend enormous energy, so the dependence becomes even less sensitive, the slope angle approaches zero. Thus, the boundary between the 2nd and $3 \mathrm{rd}$ sections for dependence $S_{s p}\left(E_{s p}\right)$ is the limit of the possibilities of mechanical valuable component disclosure (a critical level) and, in general, the use of mechanical enrichment. Consequently, there isn't sense to go over the critical level, and if such a transition is carried out, then the grinding process must be changed in the direction of energy decreasing. This raises the task of the grinding regime monitoring and the timely determination of the approximation of the grinding process transition over the critical level. In the case of such a transition, it is necessary to return the process back to a lower value of energy consumption. It means that the parameters of the grinding process should vary within narrow limits of energy consumption.

Exceeding the critical level of energy consumption shows that a significant amount of rather small particles have accumulated, but it's required their further size reduction, i.e. it is necessary to reduce the mill productivity. A decrease in the level below the critical level indicates that the grinding process has some reserve, and the grinding unit can increase its productivity. So, the main task of the fine grinding control is to find out the transition of energy consumption beyond the set level, both upwards and downwards. 
The purpose of the work is to show the possibilities of jet grinding studying based on the process acoustic signal analysis and to develop a system for controlling the mill modes to achieve its optimum productivity.

\section{Methods}

The main studies were conducted on laboratory jet countercurrent grinding units of Institute of Technical Mechanics of the National Academy of Sciences of Ukraine and the State Space Agency of Ukraine (ITM NASU \& SSAU) with a capacity of $20 \mathrm{~kg} / \mathrm{hr}$ and $0.2 \mathrm{~kg} / \mathrm{hr}$. The results were verified on an industrial jet installation of the Vilnohirsk mining and metallurgical plant (VGMK). The principle of jet mill operation is as follows. From the loading hopper (1) the material is fed into the mill. Two oncoming jets of energy carrier (3), capturing material particles in the injection system, transfer them through the accelerating tubes to the grinding zone (2). In the area of jet grinding, particles collide, break down to the required size completely or partially, then are removed by an upward flow from the chamber to the classifier (5), from which the ready product is precipitated in a cyclone (6) and unloaded from the ready product bunker (4). Unqualified particles of fraction come from the classifier in return pipes (7) for re-grinding. Thus, a closed grinding cycle with an internal classification is realized. The general scheme of the jet grinding unit with acoustic sensors is shown in Figure 1.

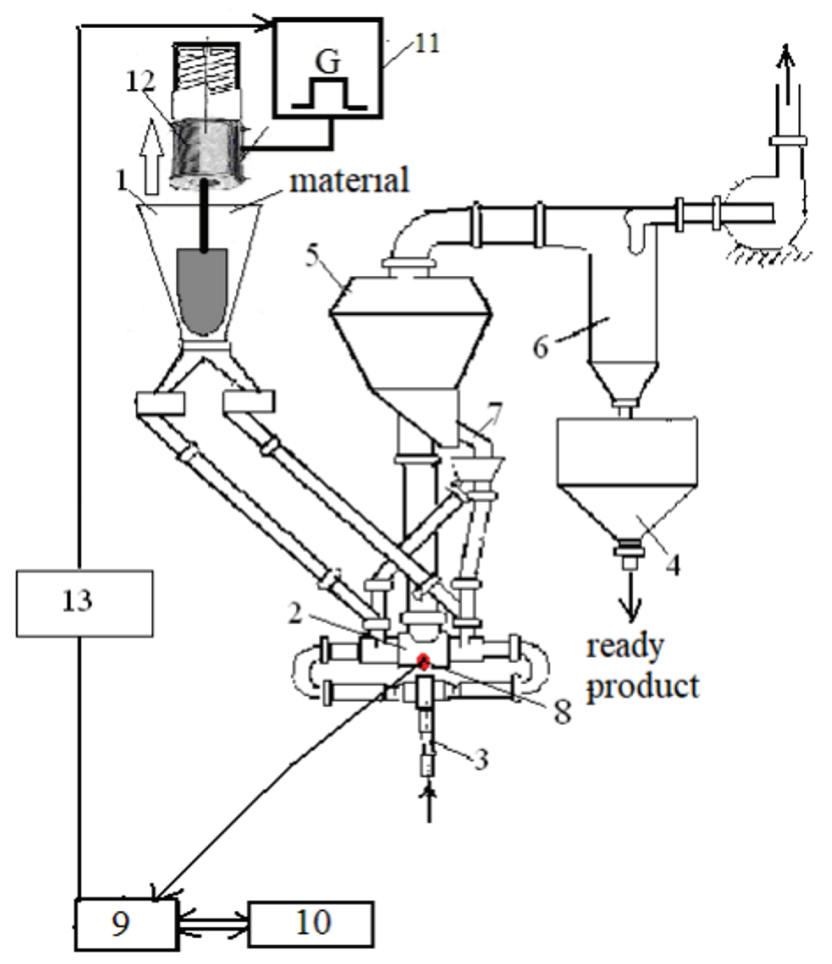

Fig. 1. Scheme of the mill with acoustic monitoring system.

ITM NASU \& SSAU together with the University "Dnipro Polytechnic" has created a technology of jet grinding research on the basis of process acoustic monitoring. To register the acoustic signals arising from the destruction, the waveguides were installed in two operation zones - inside the grinding chamber and at the exit from the classifier. The recording and processing system of the acoustic signal (AS) included: brass waveguides 
connected to piezoceramic sensors (8); analog-to-digital converter (9), connected to the computer (10). The developed hardware performed three functions: recording acoustic signals, converting them into digital form, and transferring data to a computer. For operation control of the jet installation a control system based on the results of acoustic monitoring has been developed. In Figure 1 shows its elements - a controlled hopper (1) of material loading with a transducer (11), a solenoid (12) and an automatic control unit (13).

The method of the experimental acoustic monitoring data recording of the grinding zone is described in [5]. The number of studied technological parameters includes the initial pressure of compressed air (before discharge from the nozzle), the rotor speed of the classifier, and the degree of jet loading with material, characterized by four modes: loading of the jets with material, operating mode of grinding, unloading grinding zones and over loading jet with material. The most informative parameters of acoustic monitoring are the activity $\dot{N}$ of signals, the total pulse count for a selected period of time $N_{\Sigma}$, the average amplitude, the maximum amplitude of the AS, its distribution in magnitude and the frequency of the signals with the mentioned amplitudes.

\section{Results and discussion}

The harder the material is crushed, the more sand is obtained (circulating load). However, it can be established such a regime, when the number of sands increases indefinitely, the grinding units continues to take on the load indefinitely and it can be reached such a regime when mill can't use the loading material. This can lead to mill overloading and a process emergency. To avoid such a regime, it is necessary to shut off the flow of fresh (new) material until the amount of circulating load decreases to an acceptable (critical) level. Thus, the circulating load is a control action that can significantly change the productivity of a closed grinding cycle. After this level is reached, you can again increase the loading of new material into the grinding cycle. These facts allow us to conclude that it is necessary to control the productivity of the grinding cycle according to the loaded material and to timely determine its change step when it passes over the critical level. Therefore, for process control it is necessary to determine the moment of the critical level transition by the grinding mode of material loading.

It has been established that the intensity of a new surface formation during fine grinding of solid minerals is directly proportional to the consumed energy and decreases when the grain size of the ground product reaches a certain critical value $(40-60 \mu \mathrm{m}$ for ball grinding, 10-25 $\mu \mathrm{m}$ for jet grinding) according to the type of grinding and due to the increased strength of the particles. For example, studies [6] conducted at iron ore plants for determining the dependence of the ready class yield in the grinding process on the energy consumption of the mill showed that this dependence is essentially nonlinear, and when passing over the critical level it almost loses its sensitivity. For dry jet grinding, there are also three characteristic areas of the dependence of the specific surface area on the process energy intensity, and a critical level of energy consumption is highlighted. At the same time jet grinding allows to obtain a finer product with a higher dispersion index $\left(S_{s p}\right.$ up to $8000 \mathrm{~cm}^{2} / \mathrm{g}$ ), since the grinding process in jets is more dynamic [4]. The research confirm the fact that, regardless of the grinding method, for obtaining high productivity for a thin product, it is necessary to control the process to prevent the transfer the energy intensity value to a critical value. For this purpose, an automated control system for a jet mill is being developed on the basis of the acoustic monitoring results of the fine grinding.

Studies of the connection of fine grinding technological parameters showed that the productivity on the ready product depends on the classification mode, determined by the rotor speed of the classifier (Fig. 2). 


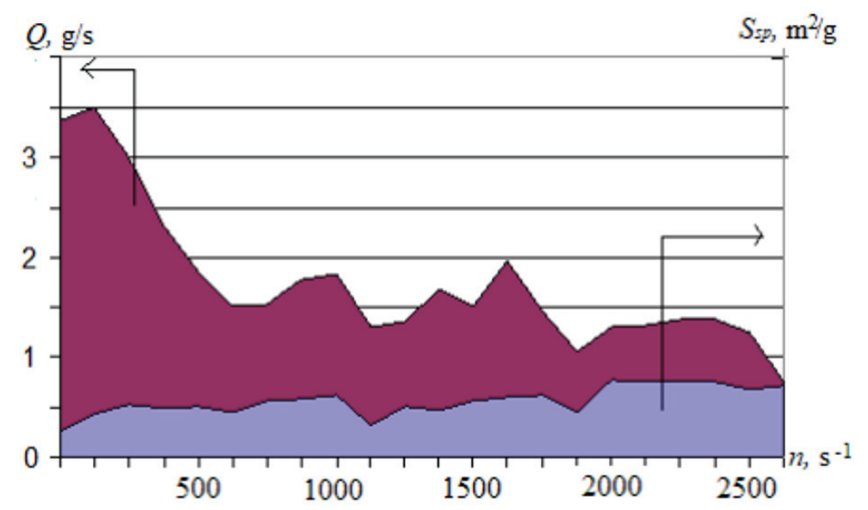

Fig. 2. Dependence of mill productivity $Q$ and the specific surface $S_{s p}$ of the ground product on the classification mode $n$ at the experimental grinding of quartz sand.

With an increase classifier speed and, accordingly, with an increase in the dispersion (specific surface) of the ground product, the productivity decreases. However, for other equal technological conditions, the jet mill productivity depends on the jet fullness with the material. The designed regression model of the jet grinding process [7] showed the prevailing influence of the loading degree of the grinding chamber on the mill productivity as a whole, while there were considered the regression dependencies of the each adopted factor influence (technological indicators: classifier speed, energy carrier pressure) on the jet mill productivity (Fig. 3).

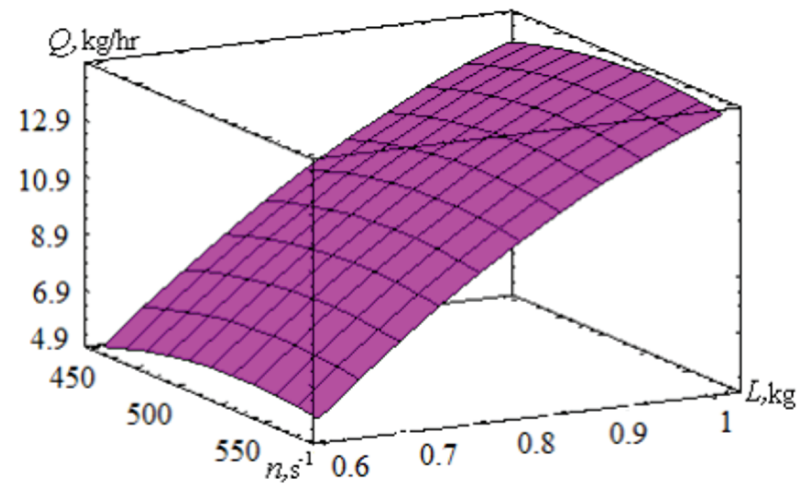

Fig. 3. Dependence of the mill productivity $Q$ on the mill load $L$ with material and the classification mode according to the results of regression modeling.

While an acoustic monitoring of a jet grinding of solid bulk materials, the problem of establishing connections between the material loading and the mill productivity with acoustic parameters during grinding was solving. An analysis of the experimental data showed that with the onset of jet unloading, a decrease in the AS activity and the middle and maximum amplitudes of the AS are observed. These factors are indicators of a decrease in the mill productivity and are used in developing a control system of the mill operating modes. Figure 4 shows the acoustic signal activity at different grinding stages: the mode of jet loading with material (1), the operating mode (2) and the mode of unloading or insufficient loading of the mill (3). Research has shown that an increase in the level of acoustic activity of the grinding zone at any stage is a factor of the increase in the particle impacts quantity and, consequently, in the grinding intensification and an increase in the mill productivity. 


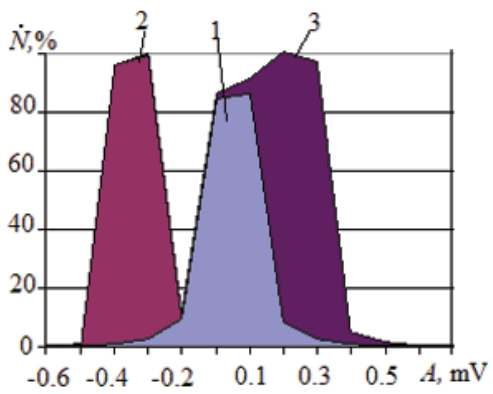

Fig. 4. Acoustic activity of the grinding zone at different grinding modes of material: the jet loading mode (1), operating mode (2), unloading mode (3).

An important parameter of acoustic monitoring of the grinding process is the amplitude of the signals. By studying the AS characteristics of the grinding zone, it was shown that the degree of mill loading with material $(50 \%)$ has a predominant effect on the amplitude of the signals. There is a little less influence of the classification mode (32\%) and even less energy carrier pressure (22\%). This conclusion coincides with previous studies of the connection of the acoustic signals characteristics with the technological parameters of the grinding process [8]. Figure 5 shows the 3-D dependence of the acoustic monitoring signal amplitude of jet grinding of fireclay on the loading degree and classification mode.

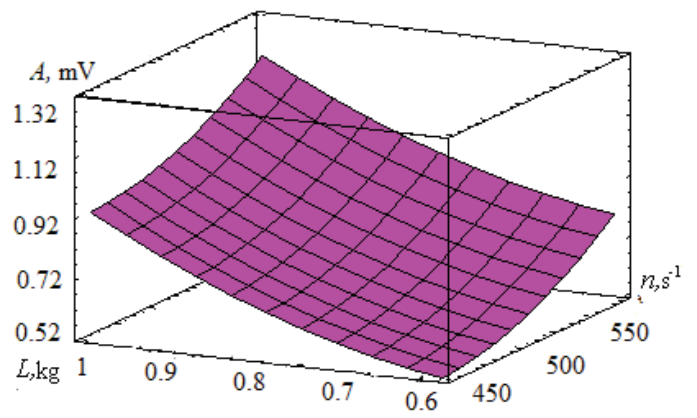

Fig. 5. Dependence of the acoustic signal amplitude of the grinding zone on the material loading of the mill and the classification mode.

Thus, the study showed that a decrease in the activity and maximum amplitudes of the acoustic signals in the grinding zone is a sign of deviation from the optimal fine grinding mode, which leads to a decrease in the mill productivity and requires timely material loading.

The general picture of the amplitude-frequency characteristics distribution of grinding slag with periodic loading of the material is shown on Figure 6, where the informative frequencies of the acoustic signals are also visible.

Studies were conducted at a frequency of $200 \mathrm{kHz}$. For this case, the load (1) lasted $4 \mathrm{~s}$, the operating mode was observed during the period of time $5 \mathrm{~s} \leq t \leq 22 \mathrm{~s}$ and the unloading (3) continued until the mill stopped $5 \mathrm{~s}$. The characteristic frequencies of the acoustic signals were in the range $55 \mathrm{kHz} \leq f \leq 83 \mathrm{kHz}$. In the grinding mode, the magnitude of the AS amplitudes is greater than at the initial stage of loading and, more importantly, than at the final stage of grinding, i.e. when the mill is under loaded. This is especially true for signals with a frequency from the informative range. 


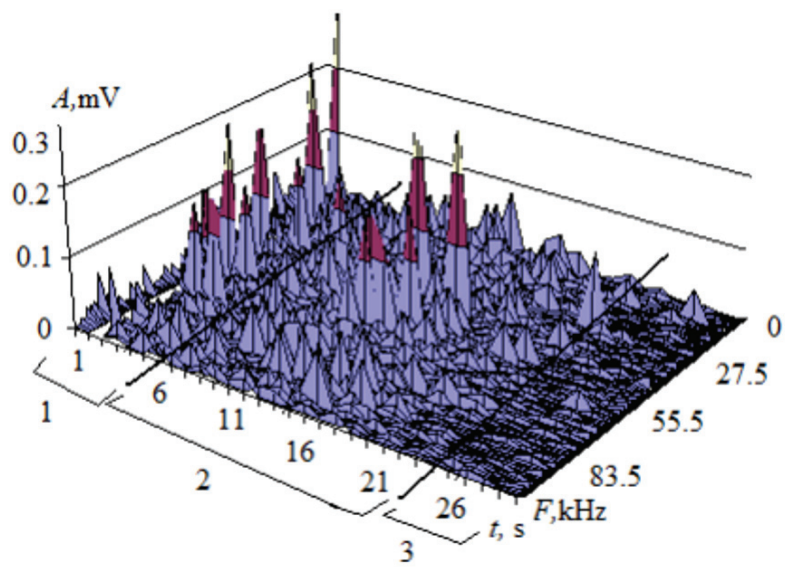

Fig. 6. The amplitude-frequency distribution of acoustic signals at different modes of blast furnace slag grinding: 1 - material loading, 2 - operating mode, 3 - mill unloading.

At the study of jet grinding process, the energy characteristics of the AS were studied [9]. Figure 7 shows the energy change of different frequency signals during the jet grinding of quartz sand from the Vilnohirsk deposit. For a signal record frequency of $400 \mathrm{kHz}$, the spectrum of informative frequencies has expanded and is defined as $65 \mathrm{kHz} \leq F \leq 125 \mathrm{kHz}$. It is established that in the grinding process the signal energy changes, the signals of the operating mode, the mode of particle dispersion has the highest energy. This is understandable, since dispersion is the final act of destruction.

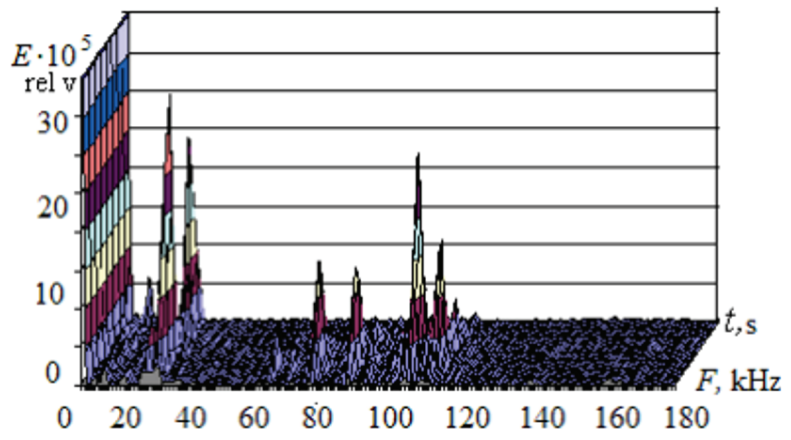

Fig. 7. Distribution of AS energy in frequency bands during the quartz sand grinding.

The data study of the acoustic monitoring information system allowed establishing the range of information frequencies of the AS. The behavior, the change in the signal amplitude magnitude of these frequencies can be defined the grinding mode. At the initial stage of the grinding process, the critical amplitude values $A_{c}$ of these signals are set. Then, during the monitoring, the initial amplitude magnitude $A$ decreases to the control one $A \leq$ $A_{c}$. The approximation of the amplitude to the control value indicates the transition of the grinding operating mode to incomplete mill loading, and a further decrease in the amplitude to $A<<A_{c}$ leads to a halt of the grinding process. Therefore, for controlling the grinding process, condition $A \approx A_{c}$ is a necessary condition for reloading the mill to continue the material grinding in the optimum operating mode.

Further research is aimed at controlling the quality of the ground product.

The dependence of the signal amplitude on the technological grinding modes and particle size during transportation of the material in the flow of energy carrier and jet grinding are shown above. However, to control the grinding product quality, it is necessary 
to control the particle size of the mixture, and for this it is not enough to analyze only the amplitude characteristics of the signals. It is necessary to consider the frequency characteristics of acoustic signals and their changes during transportation of narrow fractions and mixtures of materials. In the course of the experimental studies, recordings of acoustic signals were obtained; then, based on the Fourier method, the amplitudes and frequency signal spectra are analyzed. Analysis of the obtained records of acoustic signals and their characteristics made it possible to determine the characteristic frequencies for narrow fractions of various materials [10]. Research at the recording frequency of $400 \mathrm{kHz}$ identified four sections of the signal frequency spectrum, different in their properties: 0 $40 \mathrm{kHz} ; 40-90 \mathrm{kHz} ; 90-160 \mathrm{kHz}$ and over $160 \mathrm{kHz}$. However, only AS with frequencies of second intervals carry information about the particle size of the material and are characteristic of particular size particles. Therefore, for control of the material particle size, signals with frequencies from 40 to $90 \mathrm{kHz}$ are analyzed. As a result of experimental studies, the dependence of characteristic frequency dispersion on the particle mass and the size of the fraction in the mixture is established, this allows for the contactless determination of the particle size distribution of the material in the gas stream.

These results are verified by predicting the particle size distribution of ball milling products $r$. Experimental studies were carried out on products obtained in the second and third stages of magnetite quartzite grinding in the ball mills of the SevGOK (North mining dressing plant) [11]. Figure 8, a shows the dependence of the normalized AS frequency dispersion $d \bar{F}$ of the grinding zone on the size of the material. The frequency dispersion was normalized by the characteristic frequency $F_{\text {char }}$ for a given fraction of the material. In Figure 8,b the granulometric composition of the grinding products of stages 2 and 3 is presented. The results comparison of the calculated and experimentally obtained data of the granule composition allows us to recommend using the established dependences to control the size of the product during grinding.

The developed quality control method of the ground product includes a visual observation of acoustic signals by the operator and an additional set of acoustic signal analysis to refine the monitoring results. For industrial conditions, according to the technical requirements, it is necessary to obtain a product of a certain percentage of grades less than the control one. Therefore, the task of quality control is simplified. The characteristic frequency of the acoustic signals for the control class should be determined. Then, during acoustic monitoring of the zone behind the classifier, it's necessary to control the frequency dispersion of signals corresponding to the control class, and check the absence or presence of signals corresponding to other size classes.

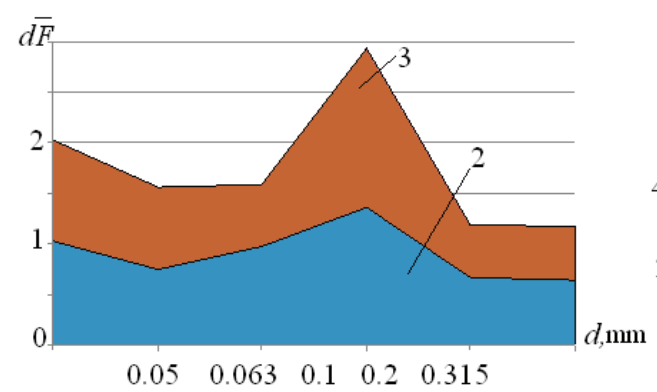

a)

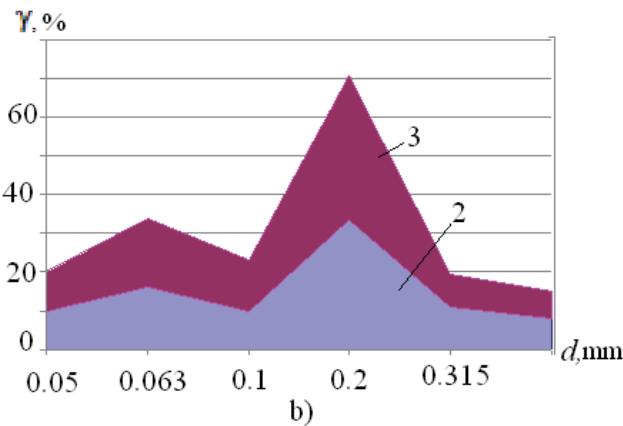

b)

Fig. 8. Dependence of the normalized frequency dispersion of the acoustic signals of the grinding zone on the size of the material (a) and the particle size distribution of the grinding products of 2 and 3 stage of ball milling (b). 
The use of the developed quality control method of the ready grinding product increases the process of determining the size of the ready product due to acoustic monitoring from 30 minutes to 1 minute. Thus, this development provides improved quality of ready product and energy savings while eliminating re-processing of the product.

The study of the connection between technological and acoustic parameters and the conclusions about the need to control the grinding mode made it possible to begin work on the of an automated control system design for the jet mill operation. Optimal parameters of the mill operation process can be realized by controlling the acoustic parameters of the grinding zone and controlling the material loading based on the search for optimal jet loading with a solid phase.

With stabilization of the grinding chamber filling at a given level, it is possible to adopt the current productivity to varying conditions. By keeping the filling volume as high as possible, the following results can be achieved:

- to use the mill in the mode of maximum possible productivity under the given conditions;

- to reduce the absolute and specific energy consumption;

- the stabilization of the volumetric filling stabilizes the circulation load in a certain extent. This is explained by the fact that the circulation load consists of two parts: the circulating volume located in the mill and the volume located in the contour of the classifying unit.

Another way to improve the operation of the grinding complexes is to directly control of the measured particle size distribution of the ground product. Indeed, the main purpose of grinding is to provide the required degree of mineral disclosure for subsequent enrichment stages, so it is obvious that the process control should be aimed at solving this problem.

Considering the acoustic monitoring capabilities described above, a combined control can be offered when a given output of the ready class with current productivity is provided by controlling the amplitude magnitude of acoustic signals in the grinding zone and dispersion of the signal characteristic frequency in the transportation zone of the ready product behind the classifier. When critical values of the monitored parameters are reached, the jet loading with the material is regulated, which leads to a change in the current productivity, and the regulation of the classification mode is made, which changes the particle size distribution of the ready product, i.e. improves its quality.

The method of controlling the jet grinding is as follows. During preliminary test grinding of each material, the technological parameters of grinding and classification (energy carrier pressure $P$, mass of material loading portion $G$, classifier rotor speed $n$, particle size and required output of the grinding product control class) are determined to achieve optimal productivity $Q^{c}$. Also during the preliminary acoustic monitoring of grinding, the control values of the acoustic signal characteristics of the operation zones are calculated (average and maximum amplitude $A_{\text {mid }}^{c}, A_{\max }^{c}$, characteristic frequency and its dispersion $F_{c h a r}^{c}, d F_{c h a r}^{c}$ ). Next, the acoustic monitoring and control unit is connected to the jet mill in its operation zones and the grinding process begins.

Figure 9 shows an algorithm for jet grinding control based on acoustic monitoring of the process. During control, there is an additional opportunity for the operator to use the "Start" and "Stop" buttons when they indicate the mode on the control panel. The controlled loading bunker is configured to perform two modes - opening the flap and closing it [12]. The quality control algorithm based on acoustic signals has a similar construction.

During industrial testing of acoustic monitoring of the zircon jet grinding in conditions of the Vilnohirsk mining and metallurgical factory, an increase in productivity on $30 \%$ was observed, with observing the required product quality. 


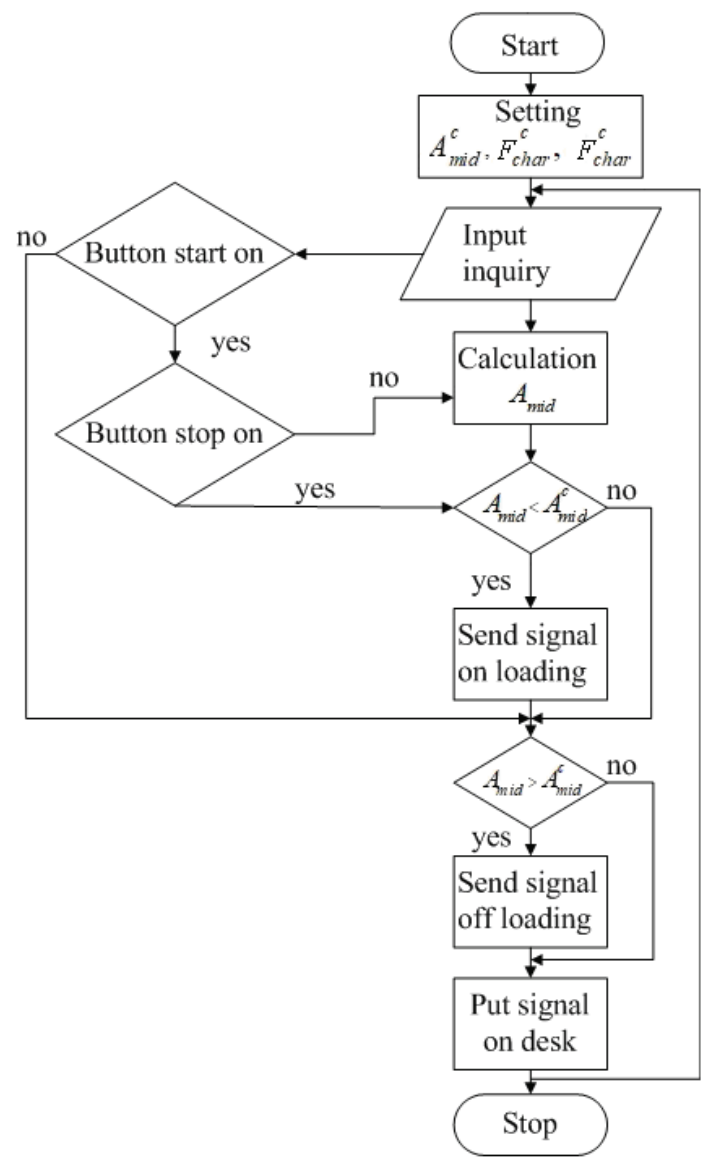

Fig. 9. The control algorithm of the jet mill modes.

\section{Conclusions}

Theoretical and experimental studies of fine grinding made it possible to establish the laws of the mill productivity increase for the process conditions change. On the basis of the connections of technological parameters and acoustic signals of the operation grinding zones, ways of control the mill productivity and grinding product quality have been developed.

The optimal parameters of the mill operation process are implemented by control the acoustic parameters of the grinding zone for optimum jet loading with a solid phase. The dispersion control of the ready product is based on acoustic monitoring of a two-phase flow in the product transportation zone.

As a result of the developed automated control system of jet grinding, the required technological parameters are achieved with reducing energy consumption and getting the control dispersion.

\section{References}

1. Andreev, S.E., Zverevich, V.V., Perov, V.A. (1965). Droblenie, izmelchenie $i$ grohochenie poleznyih iskopaemyih. Moskva: Nedra 
2. Samyigin, V.D., Mitrofanov, S.I., Barskiy, M.D. (1974). Issledovanie poleznyih iskopaemyih na obogatimost. Moskva: Nedra

3. Pivnyak, G.G., Pilov, P.I., Pryadko, N.S. (2014). Decrease of Power Consumption in Fine Grinding of Minerals. Mine Planning and Equipment Selection C Drebenstedt and R. Singhal (eds), Springer International Publishing Switserland. 1069-1079

4. Pryadko, N.S. (2016). Informatsionnyie tehnologii dlya optimizatsii tonkogo izmelcheniya materialov. Sistemnyie tehnologii modelirovaniya slozhnyih system, 427462

5. Pryadko, N.S. (2013). Akusticheskie issledovaniya struynogo izmelcheniya. Germany: LAP LAMBERT Academic Publishing.-OmniScriptum GmbH\&Co.Kg

6. Pryadko, N.S. (2016). Application of information technology for decrease of fine grinding power consumption. Engineering, Control \& Information Technologies in Geotechnical Systems, 181-186

7. Pryadko, N.S., Ternovaya, E.V., Muzyuka, L.V. (2018). Regressionnyiy analiz eksperimentalnyih rezultatov rabotyi struynoy izmelchitelnoy ustanovki s akusticheskim monitoringom. Zbirnyk naukovykh prats Natsionalnoho hirnychoho universytetu. 55, 238-247

8. Pilov, P.I., Gorobets, L.Zh., Bovenko, V.N., Pryadko, N.S. (2009). Akusticheskie i tehnologicheskie harakteristiki protsessa izmelcheniya $\mathrm{v}$ struynoy melnitse. Izvestiya vuzov. Gornyiy zhurnal, 4, 115-121

9. Pryadko, N.S. (2015). Optimization of fine grinding on the acoustic monitoring basis. Power Engineering, Control \& Information Technologies in Geotechnical System, 99108

10. Ternovaya, E.V. (2016). Analiz chastot signalov pri transportirovanii i izmelchenii syipuchih materialov v potoke. Zbahachennia korysnykh kopalyn, 63 (104), 59-65

11. Pryadko, N.S., Ternovaya, E.V. (2017). Prognoz granulometricheskogo sostava produktov izmelcheniya pri obogaschenii magnititovyih kvartsitov na osnove akusticheskogo monitoringa. Zbahachennia korysnykh kopalyn, 68 (109), 32-36

12. Muzyka, L.V., Pryadko, N.S. (2017). Metodika avtomaticheskogo upravleniya struynyim izmelcheniem na osnove modeley obekta i sistemyi upravleniya. Sistemnyie tehnologii. Regionalnyiy mezhvuzovskiy sbornik nauchnyih rabot, 2 (109), 51-58 